\title{
Implementation of the Bai \& Wierzbicki fracture criterion in QForm and its application for cold metal forming and deep drawing technology
}

\author{
Yury Gladkov ${ }^{1, a}$, Ilya Peshekhodov², Milan Vucetic ${ }^{2}$, Anas Bouguecha ${ }^{2}$, and Bernd-Arno Behrens ${ }^{2}$ \\ ${ }^{1}$ Department of Metal Forming Technology, Bauman Moscow State Technical University (BMSTU), \\ Russia \\ ${ }^{2}$ Institute of Forming Technology and Machines (IFUM), Leibniz Universität Hannover, Garbsen, \\ Germany
}

\begin{abstract}
The paper presents implementation of fracture prediction algorithm for a cold metal forming process simulation in the software QForm. Authors programmed the function for calculation of the criterion proposed by Bai and Wierzbicki. Obtained results of the simulation in QForm for a deep drawing process are compared with results of experiments. A good agreement between the simulation and experiment was achieved.
\end{abstract}

\section{Introduction}

Use of simulation systems for design of cold metal forming processes is nowadays a key task in the work of an engineer in the field of forming technology. After all, a simulation system gives the possibility to check feasibility of a process before its realization. Also it allows comparing some process alternatives and carrying out optimization that ensures high efficiency of the developed technology and lower cost of product.

In turn, simulation systems should have a possibility to predict various kinds of defects, for example: laps and flow-throw defects, underfilling of dies in bulk metal forming, but also durability of tools and sufficiency of a force capacity of the chosen equipment in bulk and sheet metal forming. A direction to improve simulation systems is prediction of a fracture due to depletion of the plasticity resource in cold forming (Fig. 1). Prediction of the remaining plasticity resource can help forecast strength and plastic properties of a forged part [1].

In the present paper the emphasis is put on a solution of the first problem: prediction of a fracture due to depletion of the plasticity resource. Fracture and cracks which appear in this case, are not predicted by simulation software automatically. To predict formation of such imperfections it is required to create a criterion for depletion of a plasticity resource or a fracture criterion. It is possible to specify such known criteria as (named by surnames of scientists who offered them): Cockroft \& Latham [2], Johnson

\footnotetext{
${ }^{\text {a }}$ Corresponding author: gladyuri@yandex.ru
}

This is an Open Access article distributed under the terms of the Creative Commons Attribution License 4.0, which permits unrestricted use, distribution, and reproduction in any medium, provided the original work is properly cited. 

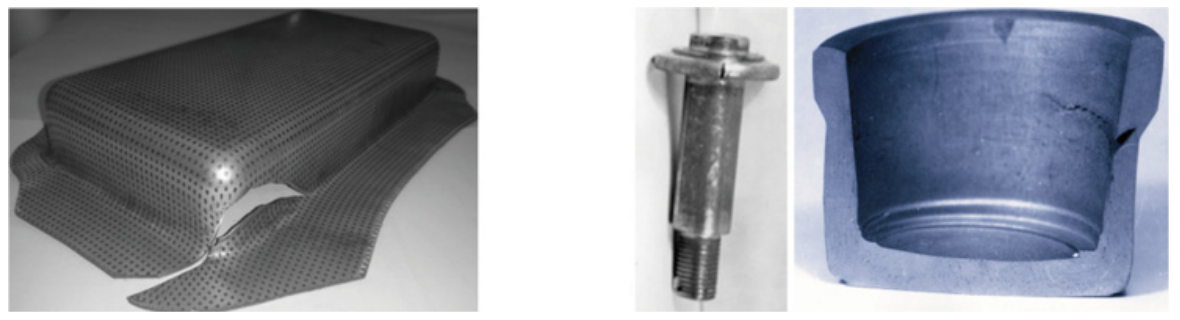

Figure 1. Examples of fracture in sheet (left) and bulk (right) metal formed part.

\& Cook [3], McClintock [4], Rice and Tracy [5], V.L. Kolmogorov [6], V.A. Ogorodnikov [7], G.D. Del [8], Yu.G. Kalpin [9], R.A. Vasin and P.A. Mossakovsky [10], and many others.

Some of these criteria have found their application among standard fracture criteria in known commercial software for forming technology. So, for example, Cockroft \& Latham criterion is included in the program QForm [11, 12], Johnson \& Cook is included in the program LS-DYNA. There are known studies on implementation of a fracture criterion in commercial software by third party research teams. Scientists have developed additional user subroutine which expands opportunities of the commercial programs $[1,13,14]$.

The attention was attracted to studies of scientists led by Professor Tomasz Wierzbicki from Massachusetts Institute of Technologies [15]. The criterion (hereinafter Bai \& Wierzbicki criterion) considering stress state triaxiality $\eta$ and Lode stress state parameter $\bar{\theta}$ was proposed in [15]. This study inspired development of a new material testing procedure for deriving of a critical deformation degree function $\bar{\varepsilon}_{p}^{\text {const }}=f(\eta, \bar{\theta})$ in the Institute of Forming Technology and Machines (IFUM), Leibniz Universität in Hanover, Germany [16, 17]. The criterion is convenient for use as it is normalized upon definition of a critical deformation degree $\bar{\varepsilon}_{\mathrm{p}}^{\text {const }}$ so that critical value for cracking condition is a value of this criterion equal to 1 . The criterion gives a fracture prediction in a wide spectrum of stress states processes where the complex loading is restricted by a critical deformation degree surface [15].

The purpose of the present research was development of the user subroutine for calculation of Bai \& Wierzbicki criterion in the widely applicable commercial software product for forming simulation QForm [11, 18]. Its basis was results of the experimental works carried out in IFUM [16, 17]. The research plan included the following: simulation of a deep drawing test case, implementation of the user subroutine in the programming language Lua, testing of sensitivity of the developed subroutine to a finite element grid density, and definition of application potential of the criterion for solving of cold die forming problems.

The created subroutine can be applied by QForm users to estimate a quality of newly developed processes of cold sheet-metal forming for the purpose to decrease level rejection because of defects due to fracture. Also the subroutine may be used for prediction of strength and plastic properties of a material and possible cracking in the course of cold die forging.

\section{Simulation of cold sheet-metal forming: Input data and comparison with the experiment}

Deep drawing was performed on a hydraulic press with the nominal force of $630 \mathrm{kN}$. The blank holder force was $320 \mathrm{kN}$. The process scheme is shown in Fig. 2. Figure $2 \mathrm{a}$ shows the workpiece made from a sheet by thickness of $1.4 \mathrm{~mm}$, overall dimensions of $240 \times 162 \mathrm{~mm}$, with edges of $127 \mathrm{~mm}$ (longitudinal) and $40 \mathrm{~mm}$ (transversal). A photo of the tool is shown in fig. 2b. The drawing punch has a right-angled shape with sizes of $76.4 \times 156.4 \mathrm{~mm}$ and corner radiuses of $6 \mathrm{~mm}$. The die dimensions are $160 \times 80 \mathrm{~mm}$ and corner radiuses equal to $3 \mathrm{~mm}$. Figure $2 \mathrm{c}$ shows the product after forming and Fig. 2e represents 


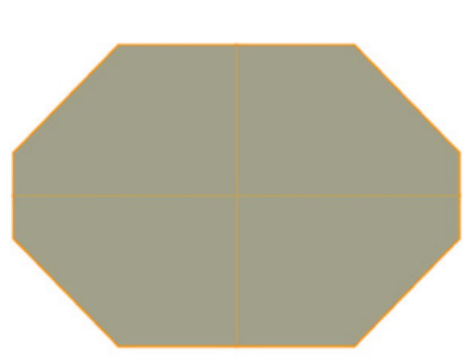

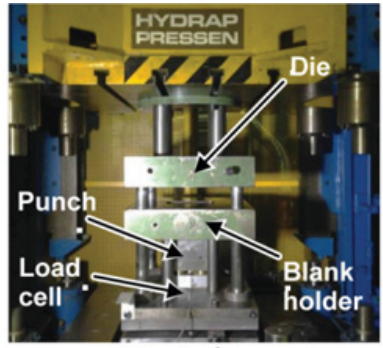

b

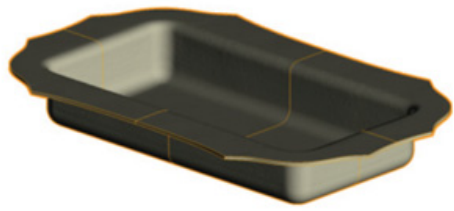

C
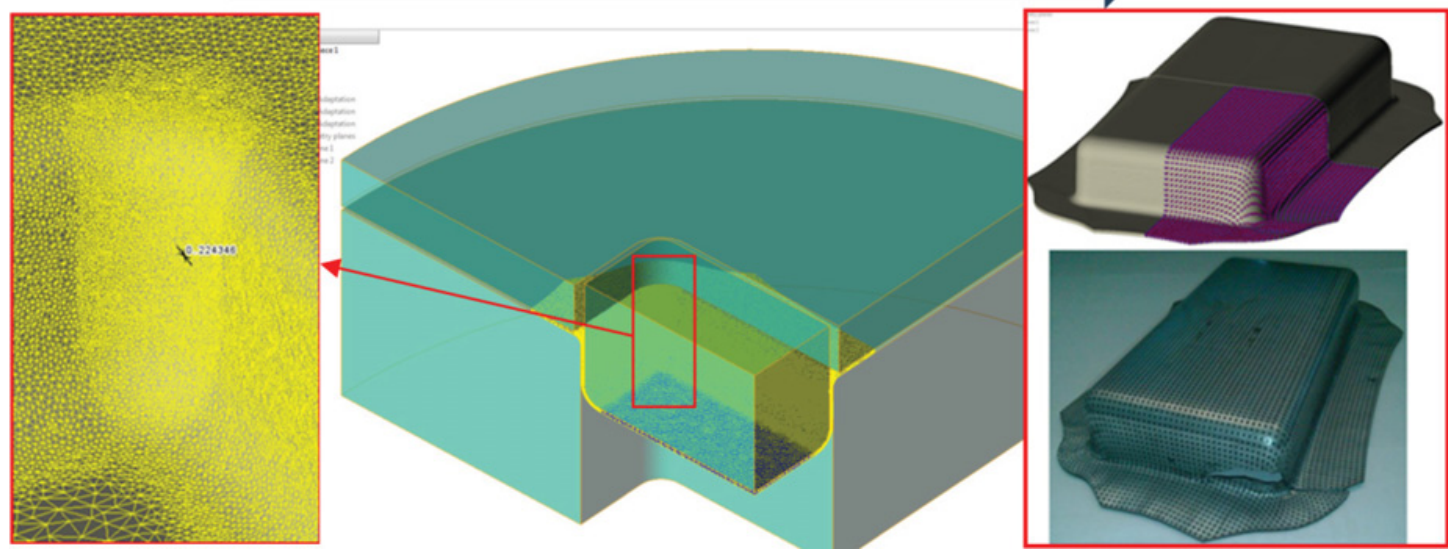

Figure 2. Deep drawing of the product "bucket": a) primary blank, b) press tool, c) formed product, d) mesh size in different zones, e) positioning of tools at the end of simulation, f) simulation result and real forged part photo.

Table 1. Material characterization function parameters.

\begin{tabular}{|l|l|l|l|l|l|l|l|l|}
\hline & $\alpha$ & $A_{\mathrm{S}}$ & $B_{\mathrm{S}}$ & $n_{\mathrm{S}}$ & $A_{\mathrm{HS}}$ & $B_{\mathrm{HS}}$ & $m_{\mathrm{HS}}$ & $n_{\mathrm{HS}}$ \\
\hline HCT600XD & 0.479 & 642 & 0.00596 & 0.660 & 757 & 1224 & 15.5 & 0.820 \\
\hline
\end{tabular}

positioning of tools (the drawing punch, the die, the blank holder) in the end of simulation. Special settings of the automatic generator of the tetrahedral finite element mesh in 3 areas have been used to provide sufficient quality of simulation (Fig. 2d). The cylinder area ("box") in an angle zone of the product has set that finite elements have a size about $0.2 \mathrm{~mm}$ that corresponds to 5-7 layers of elements over thickness.

Material characterization (Table 1): tests were conducted and the dependence of the flow stress $\sigma$ on the equivalent plastic strain was obtained for the workpiece material HCT600XD [16, 19]:

$$
\sigma=\alpha \cdot\left(A_{\mathrm{S}} \cdot\left(B_{\mathrm{S}}+\varepsilon_{\mathrm{p}}\right)^{n_{\mathrm{s}}}\right)+(1-\alpha) \cdot\left(B_{\mathrm{HS}}-\left(B_{\mathrm{HS}}-A_{H S}\right) \cdot e^{-m_{\mathrm{HS}} \varepsilon_{\mathrm{p}}^{n \mathrm{HS}}}\right.
$$

Comparisons and key sizes of the product both for experiment and simulation are shown in Fig. 3. The simulation error (for key sizes) does not exceed 3.3\%. Force diagrams are shown in Fig. 3c: obtained from the experiment [16], by simulation in Abaqus software [16] and by simulation in QForm software. The result closest to the experiment is obtained under simulation in QForm, version 7.3 with use of elasto-plastic model of the material. 


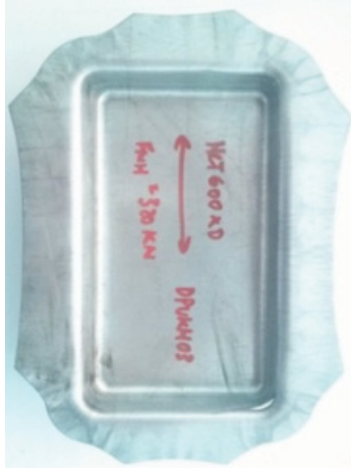

a

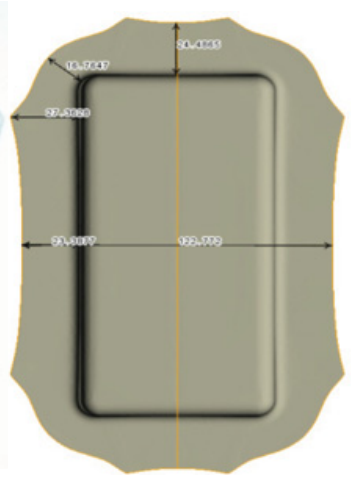

b

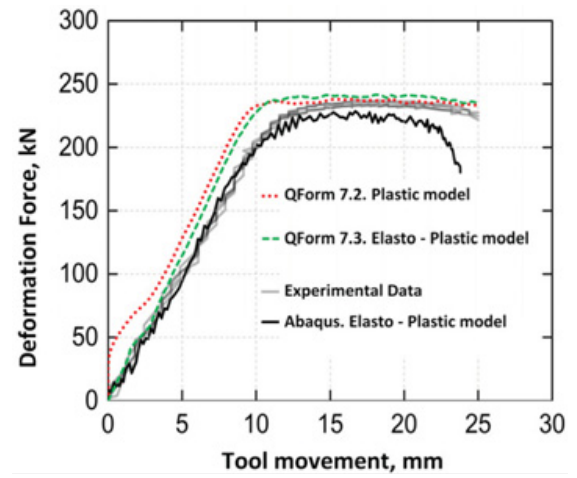

c

Figure 3. Comparison of key dimensions and force: a) the photo of the formed part, b) the view of the part after completing the simulation with results of measuring in the program QForm, c) deformation force diagrams obtained from experiment [16], Abaqus software, and QForm software.

The product obtained by simulation and a photo of the product fragment from the experiment are shown in Fig. $3 b$ for visual comparison. Trace points (in QForm) and pointwise markers (in experiment) were used for correlation of the specific areas. Difference in force values between the experimental and simulation results in both simulation programs stay within 5\% error. The replica of the product shape and a deforming force allows drawing a conclusion that the deep drawing process model in QForm replicates the experiment with an adequate exactitude, and it is possible to use the model for designing and testing of Bai \& Wierzbicki fracture criterion.

\section{Implementation of Bai \& Wierzbicki criterion: Description and simulation results}

Calculation of Bai \& Wierzbicki criterion [15] in the developed subroutine is reduced to accumulation of an index of a formability depletion $D$ :

$$
\mathrm{D}=\sum_{\mathrm{i}=0}^{\mathrm{n}} \frac{\Delta \bar{\varepsilon}_{\mathrm{P}}}{\overline{\bar{\varepsilon}}_{\mathrm{p}}^{\text {crit }}} .
$$

Where on each simulation step $\mathrm{i}=0 \ldots \mathrm{n}$ the increment of the equivalent deformation degree $\Delta \bar{\varepsilon}_{\mathrm{p}}$ is calculated numerically as the product of a strain velocity $\dot{\varepsilon}_{\mathrm{p}}$ by value of a simulation time step $\Delta t$ such approach is related by that in program QForm as the main simulation of the stress-strain state in nodes of the finite element grid is performed in deformation velocities: $\Delta \bar{\varepsilon}_{\mathrm{p}}=\Delta \bar{\varepsilon}_{\mathrm{p}} \Delta t$ ).

Critical value of the deformation degree $\bar{\varepsilon}$ crit $=\mathrm{f}(\eta, \bar{\theta})$ is calculated as the function of a stress state triaxiality $\eta$ and athe normalized Lode coefficient $\bar{\theta}$.

$$
\begin{gathered}
\bar{\varepsilon}_{\mathrm{p}}^{\mathrm{crit}}=\left[0.5 \cdot\left(D_{1} e^{-D_{2} \cdot \eta}+D_{5} e^{-D_{6} \cdot \eta}\right)-D_{3} e^{-D_{4} \cdot \eta}\right] \cdot \bar{\theta}^{2}+0.5 \cdot\left(D_{1} e^{-D_{2} \cdot \eta}-D_{5} e^{-D_{6} \cdot \eta}\right) \cdot \bar{\theta}+D_{3} e^{-D_{4} \cdot \eta} \\
\eta=\frac{1 / 3\left(\sigma_{1}+\sigma_{2}+\sigma_{3}\right)}{\sigma_{\mathrm{eq}}}
\end{gathered}
$$




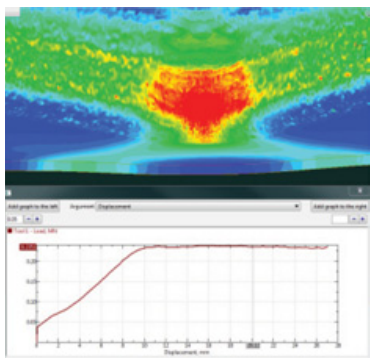

$a$

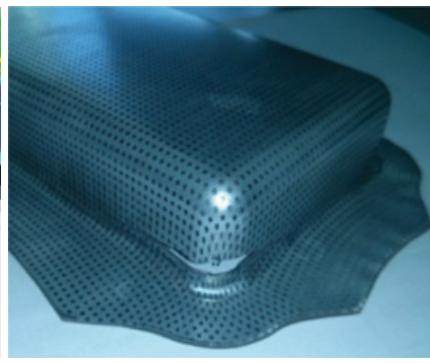

$b$

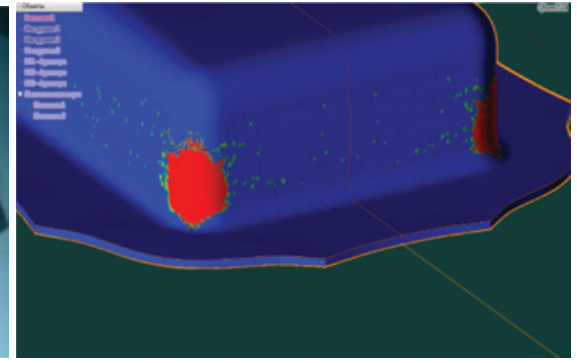

C

Figure 4. The screen layout with simulation results: a) the record corresponding to the tool movement of $20 \mathrm{~mm}$ (field "BnW" and window of the deformation force); b) photo of the product; c) the record corresponding to the tool movement of $25 \mathrm{~mm}$ (area of defect indication "Crack_View").

Values of coefficients $D_{1}=0.9702, D_{2}=5.596 \mathrm{E}-6, D_{3}=1.038, D_{4}=0.9857, D_{5}=1.803, D_{6}=$ 2.742 are determined experimentally according to the procedure [17]. So, an input information from the simulation core for each node of the grid are the main and equivalent stresses $\sigma_{1}, \sigma_{2}, \sigma_{3}, \sigma_{\text {eq }}$, and also $\bar{\theta}, \dot{\varepsilon}_{\mathrm{p}}, \Delta t$.

In the course of simulations the filtering of the values which occur as fluctuation upon numerical determination of deformation components is possible. It has been discovered that the good result can be obtained if the increment value $\Delta D$ falling in the range $0<\frac{\Delta \bar{\varepsilon}_{\mathrm{p}}}{\bar{\varepsilon}_{\mathrm{p} i t}}<$ filter $=0.3$, is used based on the result of a previous step of simulation. The value of a fluctuation filtering level filter can be set with coefficients $D_{1}, \ldots, D_{6}$.

Results of simulation are the area with the name "BnW" (see Fig. 4a) (in which value of the criterion $D$ is saved, the area "delta_BnW" (the criterion increment at the current step), the area "Eta" (the stress state triaxiality $\eta$ at a current step is saved here and the area with the name "Crack_View" (see Fig. 4c). Last area serves for indication of a zone where value D exceeds 1 that is a zone where crack occurrence is predicted.

To check the performance of the subroutine, the research was undertaken on how a finite element grid density influences results of simulation. Three alternatives of a finite element grid density were considered with sizes of elements in a crack formation zone of $0.5 \mathrm{~mm}, 0.2 \mathrm{~mm}$, and $0.1 \mathrm{~mm}$. Sizes of a zone of defect occurrence indication (the area "Crack_View") on front and rear edges of the product, and also a distance at which the defect appeared on both sides of the product (i.e. "an open defect" appeared) were studied. Almost equal times of open defect occurrences confirm a stability of criterion calculation algorithm. The sizes of defect indication zones differ by $30 \%$. Upon that, it is clear that the difference for the grids with a size of $0.2 \mathrm{~mm}$ and $0.1 \mathrm{~mm}$ can be neglected. This suggests usability of calculation with $0.2 \mathrm{~mm}$ finite element grid.

\section{Conclusions}

1. Simulation in QForm of a product obtained by sheet-metal forming replicates the corresponding experiment data with an adequate accuracy (error is less $5 \%$ ).

2. A subroutine of fracture calculation by Bai \& Wierzbicki criterion is developed.

3. It is determined that the size of a finite element grid almost does not influence a defect occurrence time on both sides of the product (no more 3\%) that proves a stability of work of the criterion calculation subroutine. 


\section{MATEC Web of Conferences}

4. It is determined that the size of a finite element grid influences a size of a defect occurrence indication zone (up to 30\%). It is recommended to check the influence of a finite element grid on a size of a defect indication zone. It was found out that in the problem, it is possible to consider a size of a finite element grid as sufficient if the element sizes equals to $0.2 \mathrm{~mm}$ in the examined zone.

5. The performed analysis of influence of the temperature increase in the cold forming process on values of the criterion, and also on volume character of a defect occurrence indication zone gives grounds to consider the use of the developed subroutine for solution of similar problems in cold die forming processes in the future.

The study was carried out at the Institute of Forming Technology and Machines (IFUM) of Leibniz Universität Hannover. The financial support in the frame of the cooperative research grant "Mikhail Lomonosov III" provided by the Ministry of Education and Science of the Russian Federation and the German Academic Exchange Service (DAAD) is gratefully acknowledged. The authors also thank "Quantor Form" LLC for the granted license on QForm software.

\section{References}

[1] A.V. Vlasov, The method of predicting the mechanical properties of the material after cold deformation on the results of mathematical modelling. Proceedings of the Conference on Metal Forming. - Kramatorsk, DSEA, No 1(34), pp. 72 - 79 (Russian, 2013)

[2] M.G. Cockcroft, D.J. Latham, Ductility and the workability of metals. J. of the Institute of Metals, 96, pp. 33 - 39 (1968)

[3] G.R. Johnson, W.H. Cook, Fracture characteristics of three metals subjected to various strain, strain rates, temperatures, pressures // Eng. Frac. Mech., 21, pp.31 - 48 (1985)

[4] F.A. McClintock, A criterion of ductile fracture by the growth of holes. Journal of Applied Mechanics, 35, pp. 363 - 371 (1968)

[5] J.R. Rice, D.M. Tracey, On the ductile enlargement of voids in triaxial stress fields. Journal of the Mechanics and Physics of Solids, 17, pp. $201-217$ (1969)

[6] V.L. Kolmogorov, Mechanics of Metal Forming. Ekaterinburg, 836 p (Russian, 2001)

[7] V.A. Ogorodnikov, Evaluation deformability of material at metal forming. Kiev: Vishya shcola, 174 p. (Russian, 1983)

[8] Del G.D. Plasticity of deformed material // Physics and technology of high pressure, No 11, pp. 28 - 32 (Russian, 1983)

[9] Yu.G. Kalpin, V.I. Perfilov, P.A. Petrov, V.A. Ryabov, Yu.K. Filipov, Deformation resistance and plasticity in metal forming. Mashinostroenie, Moscow, 243 p. (Russian, 2011)

[10] R.A. Vasin, P.A. Mossakovsky, Journal of Applied Mathematics and Mechanics 75 (2011)

[11] Documentation and user guide of QForm on http://www . qform3d.co.uk

[12] A.V. Belevich, D.M. Babin, Yu.A. Gladkov, A.V. Aborkin, Simulation and research of metal forming processes. Vladimir State University, 181 p. (Russian, 2012)

[13] N.V. Biba, S.A. Stebunov, S.V. Smirnov. Application of adaptive damage theory for optimization of cold bulk metal forming, Proceedings of the 7TH International Conference on Numerical Methods in Industrial forming processes, Toyohashi, Japan (2001)

[14] O. Bylya, N. Biba, A. Vlasov, R. Vasin, The analysis of different damage accumulation models for simulation of hot and warm working of alfa+beta titanium alloys. On http://qform3d.co.uk/db_files/47/280.pdf

[15] Y. Bai, T. Wierzbicki A new model of metal plasticity and fracture with pressure and Lode dependence / International Journal of Plasticity 24, pp. 1071-1096 (2008) 


\section{ICNFT 2015}

[16] B.-A. Behrens, M. Vucetic, I. Peshekhodov Effiziente Charakterisierung und Modellierung des Fließ- und Versagensverhaltens von Dualphasenstählen. Umformtechnisces Kolloquium, Hannover, pp. 77-97 (German, 2014)

[17] B.-A. Behrens, M. Vucetic, I. Peshekhodov Calibration of fracture initiation models for advanced high-strength sheet steels in a wide range of stress states using a uniaxial tensile testing machine. Proceedings of the IDDRG 2014 Conference, Paris, pp. 252-257 (2014)

[18] N.V. Biba, S.A. Stebunov, Yu.A. Gladkov, P.S. Mordvincev QForm - unique software for metal forming simulation // KShP magazine, No 1, pp. 36-42 (Russian, 2011)

[19] B.-A. Behrens, A. Bouguecha, M. Vucetic, I. Peshekhodov Characterisation of the quasi-static flow and fracture behaviour of dual - phase steel sheets in a wide range of plane stress states. Archives of Civil and Mechanical Engineering 12, No. 4, pp. 397-406 (2012) 